\title{
Moral Hazard and Free Riding in Collective Action
}

\author{
Vincent Anesi* \\ University of Nottingham
}

August, 2006

\begin{abstract}
Most political and economic theorists point to moral hazard in teams as the main obstacle to lobbies' collective action. In this paper, we address this important issue with a coalition-formation game. In the process of doing so, we characterize equilibrium lobby structures both in the absence and in the presence of moral hazard. Three notable results emerge from such an exercise: (i) an equilibrium lobby structure exists under both specifications of the model, (ii) moral hazard in teams may raise large groups' equilibrium lobby size, and (iii) it may also raise the total contribution to lobbying of large groups with low organizational costs.
\end{abstract}

JEL classification: C72, D72, H41

Keywords: Collective action, Moral hazard in teams, Lobby formation, Free-rider problem

\footnotetext{
*Address: School of Economics, Room B18, The Sir Clive Granger Building, University of Nottingham, University Park, Nottingham NG7 2RD, United Kingdom . Email: vincent.anesi@nottingham.ac.uk. I would like to thank Helmuth Cremer, Philippe De Donder, Kai A. Konrad, Michel Le Breton, and Shlomo Weber for valuable comments and suggestions. I am also grateful to Paul Belleflamme, Francis Bloch, Robert Dur, Joan Esteban, Debraj Ray, and the audience at the CESifo Area Conference on Public Sector Economics 2006 and at the 15th Aix-Marseille SSIEIO for helpful discussions.
} 


\section{Introduction}

In many situations of interest in economics and political science, agents with common goals form groups or organizations. The achievement of these goals often depends on nonverifiable, individual contributions by group members to the collective cause. Then, the activity carried out by such groups is referred to as collective action; political influence, labor unions, military alliances, and global pollution control, being canonical examples. For concreteness, the present paper focuses on self-interest groups.

There is now a large literature on inefficiencies arising in groups or organizations' collective action, dating back to the seminal work of Olson (1965). All of these papers point to free riding within organized groups (or moral hazard in teams) as an important obstacle to collective action: Each member of the group has an incentive to benefit from the effort contributed by other members while contributing insufficiently herself. As the incentive to shirk grows with the group's size, large groups are consequently expected to be the most affected by the free-rider problem. Thus, we can conjecture that, paraphrasing Mueller (2003, p. 473),

the appearance of organizations that effectively represent large numbers of individuals requires that separate and selective incentive(s) be used to curb free-riding behavior.

The point we wish to make in this paper is that this apparently compelling conclusion may actually be questioned. Much of the analysis of collective action has been concerned with the free-rider problem within organized groups. However casual observation suggests that, lobbying, as many similar collective-action situations, involves a preliminary stage that does not explicitly appear in the Olsonian theory: before engaging effectively in activities of interest to their members, groups have to get organized. That is, potential members of a lobby must first bear initial organization costs that consist of developing administrative structures, or communication networks, to name a few. A complete analysis of the implication of moral hazard in teams on collective action should, accordingly, include the lobby-formation stage.

Thus, this paper asks the following question: does moral hazard in teams impede large groups' collective action in a setting that takes lobby formation into consideration? To answer this question, we cast the analysis of the free-rider problem within a two-stage framework in which groups first organize in a lobby, and then compete to further their interests. An immediate consequence of this assumption is that, in addition to the traditional free-riding phenomenon described in the collective-action literature, another 
one appears here: At the lobby formation stage, some members of a given group may choose to remain out of the lobby that represents the group's interests. When we refer to free-riding, we must thus distinguish between the behavior of individuals who do not join the lobby in the first stage of the game, and the behavior of those who join the lobby but shirk in the second stage. To avoid any confusion, we use hereon the term moral hazard in teams (Holmström, 1982) to designate free riding within organized lobbies, while a free-rider is exclusively referred to as any individual who stays out of a lobby while benefiting from its action.

Examples of such situations abound in collective action. Among the most conspicuous of these are environmental lobbies and some labor unions, the members of which engage in activities that also benefit many non-members. Moreover, most of these activities (demonstrations, letter-writing, telephone campaigns) are particularly subject to moral hazard. But this coexistence of free-riding and moral hazard phenomena is not limited to lobbying. Another example is provided by international environmental agreements. While some countries do not participate, some others sign the agreement but then cheat on it (see Petrakis and Xepapadeas, 1996).

The process through which lobbies compete to influence government policy is extremely complex. Our aim here is to concentrate on moral hazard in teams within organized lobbies, and then to abstract from any other complexity that such a situation might realistically entail. Esteban and Ray (2001) offer a model of collective action that appears to be particularly well suited to this purpose. In this model, groups of identical individuals hold different views about the relative desirability of feasible alternatives, and each would like its favorite to be chosen. The simplification taken here is to let influence mechanisms lurk in a win-probability function that maps lobbies' aggregate contributions into a probability distribution over favored alternatives. Although this is a highly abstract version of groups' competition for influence, it contains all the elements needed to study the impact of moral hazard in teams on lobby formation and collective action, which is the main focus of the present paper. We model the lobby formation process as Nash, in the sense that an equilibrium structure is one in which no individual wants to leave his or her lobby, given the equilibrium behavior of the other individuals in the society, and no individual has an incentive to become a lobbyist.

We consider two different specifications of this model, which both possess an equilibrium lobby structure (Proposition 1). To highlight the impact of moral hazard on groups' ability to organize in a lobby, we first study the case in which individual contributions are verifiable, and cooperation between lobby members is then feasible. This benchmark case displays a noteworthy feature: whatever the value of the exogenous cost of getting organized, 
the equilibrium size of each lobby cannot exceed some upper-bound, which does not depend on the total size of the group it represents (Proposition 2). Therefore, large groups (with a membership that exceeds the upper-bound under consideration) comprise free-riders when there is no moral hazard in teams. We then do the same exercise with a more realistic framework in which contributions are not verifiable. Proposition 3 establishes that there is no upper-bound, except the group size, on a lobby's equilibrium membership: its equilibrium size can be arbitrarily large as long as its fixed costs are sufficiently low. Our model thus predicts that the lobby's membership of large groups with low fixed costs is larger with than without moral hazard in teams. This is a somewhat surprising, but actually quite intuitive, result: the non-verifiability of individual contributions allows lobbyists to reduce their contribution costs, and thus raises individuals' incentives to become lobbyists. If it is too costly for an individual to join the lobby that defends her interests, she may refrain from doing so. By lowering the cost of being a lobby member, moral hazard in teams favors participation in lobbying activities. In fact something stronger is true: provided that a group's size is large enough and its fixed organization cost is sufficiently low, moral hazard in teams raises that group's total contribution to lobbying (Proposition 4). This last result stands in sharp contrast with the above-mentioned Olsonian conjecture, inviting a reassessment of the role of moral hazard in teams in collective action. In particular, curbing moral hazard within an organized group, as urged by Olson (1965), may sometimes have a perverse effect, undermining individuals' incentives to take part in collective action.

The paper is organized as follows. In Section 2 we present the model. Existence and characterization results are presented in Section 3. Finally, Section 4 is devoted to concluding remarks. Proofs are gathered in the appendix.

\section{Related Literature}

In The Logic of Collective Action, Olson (1965) has offered the first steps of a theory on collective action. A large literature has followed from this initial work, which explores the relationship between group size and collective action. ${ }^{1}$ The most recent theoretical contributions are due to Agrawal and Goyal (2001), and Esteban and Ray (2001). Another branch of this literature, including Petrakis and Xepapadeas (1996) and Pecorino (1998, 2001), studies groups' ability to overcome the free-rider (or moral-hazard) problem. To

\footnotetext{
${ }^{1}$ We refer the reader to Sandler and Hartley (2001) for a recent account of the literature on collective action.
} 
the best of our knowledge, the present paper is the first contribution that questions the negative impact of moral hazard in teams on collective action.

Most of the political-economy literature on lobbying has been focused on the influence process (an extensive survey can be found in Grossman and Helpman, 2001). Although these authors clearly recognized the importance of group formation in the lobbying process, issues of formation and organization have been little discussed in formal models. Focusing on the case of trade policy, Mitra (1999) was the first contribution to study lobbying with a model involving an explicit coalition-formation stage: In the first stage of the game, individuals with common interests in the trade policy decide whether or not to bear the cost of getting organized; in the second stage, groups that have formed lobby the government in order to influence its policy. Mitra (1999) however assumes that, once formed, lobbies act as a single entity, and consequently ignores the free rider problem raised by the collective-action literature. Felli and Merlo (2006) offer a theory of endogenous lobbying centering on a bargaining game between an elected decision-maker and a coalition of lobbies chosen by the latter. Lobbying is endogenous in their model, for the policy-maker selects the lobbies that participate in the lobbying process.

Recently, Le Breton and Salanié (2003), and Martimort (2004) have explored lobby formation in common-agency settings. Both papers emphasize how government's private information affects the participation in the lobbying process. But there is no explicit organization step in their models, as participation means nonzero contribution. They have little to say about biases in collective action that may result from groups' organization. Our contribution here is in examining the linkage between moral hazard in teams and collective action via its effects on lobby formation.

Our analysis of collective-action problems is also related to recent papers in the literature on coalition-formation games. The paper most closely related to our model is that by Espinosa and Macho-Stadler (2003), who study the impact of moral hazard in teams on the formation of partnerships in a model of Cournot competition. In their paper, coalition formation is modelled as an infinite-horizon sequential game. They show that, when moral hazard within partnerships is not too severe, the coalition structure may be more concentrated then it would be in the absence of moral hazard.

\section{The Model}

As mentioned in the introduction, a natural way to model lobby formation in collective-action settings is as a two-stage process in which each lobby first forms, and then competes with other organized groups to influence decision- 
making. Following Mitra (1999), we thus study a two-stage lobby-formation game with the following structure ${ }^{2}$ :

1. Lobby formation: Every individual decides whether to join or not the organized group that represents her interests.

2. Collective action: Lobbies that have formed play a collective-action game.

This formalism allows us to distinguish between two free-riding phenomena. The first may arise in the first stage of the game, when some individuals do not join the lobby, although benefiting from its action in the second stage. The second, called moral hazard in teams throughout the paper, arises in the second stage when effort is not verifiable and lobby members contribute insufficiently to the lobbying action.

We will study (pure strategy) subgame perfect Nash equilibria of this game. Moving backward, we first describe the collective-action stage, and then turn to lobby formation.

\subsection{Collective Action}

In this subsection we sketch the abstract collective-action model proposed by Esteban and Ray (2001). We will describe this model below, but refer the reader to that paper for an in-depth discussion of the basic assumptions.

Consider a society in which individuals belong to one of $G$ distinct groups, labelled with an index $i \in\{1, \ldots, G\}$. Let $n_{i} \geq 2$ be the size of group $i$, and $n$ be the size of the entire population: $n \equiv \sum_{i} n_{i}$. The members of each group share a common interest in the choice of a collective good (public project, government...) for the whole society. $G$ mutually exclusive alternatives are available: members of group $i$ favor alternative $i$. Each member of group $i$ enjoys a per-capita benefit of $w_{i}>0$ if alternative $i$ is chosen by the society, and a benefit normalized to be zero if another alternative is chosen. ${ }^{3}$

Group $i$ 's interests may be defended by a lobby (or organized group), called lobby $i$, with membership $c_{i} \in\left[0, n_{i}\right]$. In the original version of the model, the $c_{i}$ 's are exogenously given and equivalent to the total size of each group $\left(c_{i}=n_{i}, i=1, \ldots, G\right)$. We postpone to the next subsection to explain

\footnotetext{
${ }^{2}$ Murdoch, Sandler, and Vijverberg (2003) use a similar framework in the context of an environmental treaty. Nations first decide whether or not to participate and then they choose their level of participation.

${ }^{3}$ Esteban and Ray (2001) distinguish between the public and the private components of the collective good. This distinction would not play any role in the present analysis.
} 
how, in the present paper, individuals in the society decide to become either lobbyists or free-riders.

Collective action takes place as follows: Within each lobby, individuals simultaneously contribute a certain level of effort to the collective cause, thus yielding lobbies' aggregate efforts. Let $A_{i}$ denote lobby $i$ 's aggregate effort, and $A_{-i}$ be the aggregate effort of lobby $i$ 's opponents plus some positive term $A_{0}$. This parameter models the presence of a group of individuals who, for some reasons, are unable to organize in order to influence the decisionmaking process. $A_{0}$ thus represents the decision-maker's consideration for those individuals irrespective of other groups' contributions. It can also reflects the presence of an alternative that only benefits the decision-maker, as diversion of public funds for private use. Actually, assuming $A_{0}>0$ allows us to sidestep discontinuity and existence problems. ${ }^{4}$ The probability for alternative $i$ to be chosen is then given by

$$
\pi_{i}\left(A_{i}, A_{-i}\right) \equiv \frac{A_{i}}{A_{i}+A_{-i}}
$$

The cost of contributing effort level $a$ to the lobbying is given by $v(a)$, where $v$ is an increasing, continuous, strictly convex function with $v^{\prime}(0)=0$. As in Esteban and Ray (2001), the shape of the $v$ function will play an important role in the statement of the formal results. More precisely, we will use the following convexity index:

$$
\alpha(a) \equiv \frac{a v^{\prime \prime}(a)}{v(a)}
$$

which can be interpreted as the elasticity of the marginal rate of substitution between reward and effort. For technical convenience, $\alpha$ is assumed to be bounded from above.

Given group efforts $\left(A_{1}, \ldots, A_{G}\right)$, the expected utility of a member of lobby $i$ contributing $a$ is therefore equal to

$$
\pi_{i}\left(A_{i}, A_{-i}\right) w_{i}-v(a)
$$

Two possible formulations of the model will successively be studied. We begin with the verifiable-contribution case because it creates a benchmark against which to measure the impact of moral hazard in teams on groups' collective action.

\footnotetext{
${ }^{4}$ To see this, suppose $A_{0}=0$ and consider a continuation game in which only one lobby has formed. This game has no Nash equilibrium, and therefore the general game has no subgame perfect Nash equilibrium.
} 


\section{Collective Action when Effort is Verifiable}

Consider first the equilibrium arising in this model when lobbyists' contribution levels are verifiable. In such a case, cooperation within lobbies is feasible, for lobbyists can write ex ante contracts contingent on their individual contribution. We assume that each lobby's objective is to maximize its members net welfare, with the same contribution for all members. A Nash equilibrium of this game is thus a profile $\left(a_{1}, \ldots, a_{G}\right)$, such that each group $i$ maximizes

$$
c_{i}\left[\frac{c_{i} a_{i}}{c_{i} a_{i}+A_{-i}} w_{i}-v\left(a_{i}\right)\right]
$$

with respect to $a_{i}$, taking the equilibrium aggregate effort exerted by the other groups as given. Hence, if $\left(a_{1}, \ldots, a_{G}\right)$ is a Nash equilibrium, these effort levels must satisfy the following first-order condition:

$$
\frac{c_{i} w_{i}}{c_{i} a_{i}+A_{-i}}\left(1-\frac{c_{i} a_{i}}{c_{i} a_{i}+A_{-i}}\right)=v^{\prime}\left(a_{i}\right),
$$

for every $i=1, \ldots, G$.

Following the reasoning used in Esteban and Ray (2001), it is easy to check that the system of equations defined by (1) has a unique solution for every vector $\left(c_{1}, \ldots, c_{G}\right) \in \mathbb{R}_{+}^{G}$. Let the collection of functions $\left\{a_{i}\left(c_{i}, c_{-i}\right)\right\}_{i=1}^{G}$ stand for these solutions, where $c_{-i}$ denotes the vector of memberships of all lobbies except $i$.

\section{Collective Action with Moral Hazard in Teams}

We now turn to the situation in which effort levels are not verifiable. In this case, lobbyists' behavior is subject to moral hazard: Instead of maximizing the lobby's aggregate welfare, each member of lobby $i$ chooses a contribution, $a$, which maximizes her individual expected utility

$$
\frac{A_{i}}{A_{i}+A_{-i}} w_{i}-v(a)
$$

taking as given the other individuals' contribution. The level of effort $a_{i}$ exerted by the members of lobby $i$ must therefore satisfy the first-order condition

$$
\frac{w_{i}}{c_{i} a_{i}+A_{-i}}\left(1-\frac{c_{i} a_{i}}{c_{i} a_{i}+A_{-i}}\right)=v^{\prime}\left(a_{i}\right)
$$

for every $i=1, \ldots, G$.

As in the case without moral hazard, one can show that the system of equations (2) defines the unique Nash equilibrium of the second-stage game. 
Denoting by $\left\{a_{i}^{m}\left(c_{i}, c_{-i}\right)\right\}_{i=1}^{G}$ the solutions of these equations, we can immediately note that $a_{i}^{m}\left(c_{i}, c_{-i}\right)<a_{i}\left(c_{i}, c_{-i}\right)$ whenever $c_{i}>1$. Hence, moral hazard leads to a decrease in the individuals' effort levels. This occurs because each individual fails to consider the benefits for other lobbyists of her contribution to the lobbying activity.

Up to this point, we have taken each lobby's membership as given. We now propose a model of lobby formation in which lobbies' memberships are endogenously derived.

\subsection{Lobby Formation and Equilibrium Structures}

In the first-stage of the game, all individuals in society simultaneously choose whether to join or not the lobby that defends their interest. That is, a player's action set in this stage is $\{$ in, out $\}$. As in Mitra (1999), we assume that forming a lobby involves a fixed cost $F_{i}$ for group $i$. Here lobby formation is regarded as a sunk investment (establishing links with politicians, building an administrative structure and communication networks). Those in society who do not initially bear that set-up investment do not have access to lobbying during the decision process. ${ }^{5}$

Since players perfectly anticipate the effort levels that will be exerted in the second stage, their payoffs can be expressed as functions of lobbies' sizes $\left(c_{1}, \ldots, c_{G}\right)$. We describe these payoffs using the functions $P_{i}, Q_{i}$ in the absence of moral hazard, and $P_{i}^{m}, Q_{i}^{m}$ in the presence of moral hazard: If an individual of group $i$ plays "in", she becomes a lobbyist and her payoff when $c_{i}>0$ is given by

$$
P_{i}\left(c_{i}, c_{-i}\right) \equiv \frac{c_{i} a_{i}\left(c_{i}, c_{-i}\right)}{A_{0}+\sum_{j=1}^{G} c_{j} a_{j}\left(c_{j}, c_{-j}\right)} w_{i}-v\left(a_{i}\left(c_{i}, c_{-i}\right)\right)-\frac{F_{i}}{c_{i}}
$$

in the absence of moral hazard, and

$$
P_{i}^{m}\left(c_{i}, c_{-i}\right) \equiv \frac{c_{i} a_{i}^{m}\left(c_{i}, c_{-i}\right)}{A_{0}+\sum_{j=1}^{G} c_{j} a_{j}^{m}\left(c_{j}, c_{-j}\right)} w_{i}-v\left(a_{i}^{m}\left(c_{i}, c_{-i}\right)\right)-\frac{F_{i}}{c_{i}}
$$

with moral hazard. If an individual of group $i$ plays "out", she has no effect on the future play since the second stage of the game only involves lobbyists.

\footnotetext{
${ }^{5}$ This assumption is comforted by a recent empirical analysis by Hojnacki and Kimball (2001). Their study confirms that political action committee (PAC) affiliates in the US enjoy significantly greater access to members of Congress than non-affiliated lobbyists. Furthermore, they show that this lobbying advantage stems from the base of support PACs have established around the country, and not from their contributions.
} 
This individual is a free-rider in that she benefits from the lobbying without contributing to it; she thus receives

$$
Q_{i}\left(c_{i}, c_{-i}\right) \equiv \frac{c_{i} a_{i}\left(c_{i}, c_{-i}\right)}{A_{0}+\sum_{j=1}^{G} c_{j} a_{j}\left(c_{j}, c_{-j}\right)} w_{i}
$$

or

$$
Q_{i}^{m}\left(c_{i}, c_{-i}\right) \equiv \frac{c_{i} a_{i}^{m}\left(c_{i}, c_{-i}\right)}{A_{0}+\sum_{j=1}^{G} c_{j} a_{j}^{m}\left(c_{j}, c_{-j}\right)} w_{i} .
$$

Consider now the subgame-perfect Nash equilibria of the game without moral hazard. In a subgame perfect equilibrium with memberships $\left(c_{i}, c_{-i}\right)$, every individual who has chosen to join a lobby does at least as well by doing so as she would do if she were to change her decision to "out", given the anticipated outcome of the second-stage collective-action game. Put formally,

$$
P_{i}\left(c_{i}, c_{-i}\right) \geq Q_{i}\left(c_{i}-1, c_{-i}\right) .
$$

Similarly, every individual who has chosen to remain out of her lobby does at least as well by doing so as she would do if she were to change her decision to "in":

$$
Q_{i}\left(c_{i}, c_{-i}\right) \geq P_{i}\left(c_{i}+1, c_{-i}\right) .
$$

To use the language of coalition-formation games, conditions (3) and (4) ensure internal and external stability, respectively. ${ }^{6}$ The same reasoning applies to the equilibria of the game with moral hazard.

The next definitions make precise the meaning of equilibrium structure in the lobby formation game under both specifications of the model. For notational ease, we define the stability functions $\left\{L_{i}\left(c_{i}, c_{-i}\right)\right\}_{i=1}^{G}$, as

$$
L_{i}\left(c_{i}, c_{-i}\right) \equiv P_{i}\left(c_{i}, c_{-i}\right)-Q_{i}\left(c_{i}-1, c_{-i}\right) .
$$

These functions, introduced by Carraro and Siniscalco (1997), capture individuals' incentives to become (and remain) lobbyists. They will be handy when we come to study equilibrium memberships in Section 3.

Definition 1 In the absence of moral hazard, an equilibrium structure of the lobby formation game is a profile $\left(c_{1}^{*}, \ldots, c_{G}^{*}\right) \in(\{0\} \cup \mathbb{N})^{G}$ such that:

(i) $c_{i}^{*} \leq n_{i}$,

(ii) $L_{i}\left(c_{i}^{*}, c_{-i}^{*}\right) \geq 0$ if $c_{i}^{*}>0$, and

(iii) $L_{i}\left(c_{i}^{*}+1, c_{-i}^{*}\right) \leq 0$ if $c_{i}^{*}<n_{i}$,

for every $i=1, \ldots, G$.

${ }^{6}$ The concept of internal and external stability was introduced by d'Aspremont et al. (1983) who used it to study cartel stability in single-coalition games. 
The last two conditions of Definition 1 correspond to internal and external stability, respectively. They ensure that, in equilibrium, nobody wants to leave (condition (ii)) or to join (condition (iii)) a lobby. Condition (i) is a natural feasibility condition. We similarly define an equilibrium structure under moral hazard. As above, we first introduce the stability functions $\left\{L_{i}^{m}\left(c_{i}, c_{-i}\right)\right\}_{i=1}^{G}$ :

$$
L_{i}^{m}\left(c_{i}, c_{-i}\right) \equiv P_{i}^{m}\left(c_{i}, c_{-i}\right)-Q_{i}^{m}\left(c_{i}-1, c_{-i}\right) .
$$

Definition 2 With moral hazard in teams, an equilibrium structure of the lobby formation game is a profile $\left(c_{1}^{m}, \ldots, c_{G}^{m}\right) \in(\{0\} \cup \mathbb{N})^{G}$ such that:

(i) $c_{i}^{m} \leq n_{i}$,

(ii) $L_{i}^{m}\left(c_{i}^{m}, c_{-i}^{m}\right) \geq 0$ if $c_{i}^{m}>0$, and

(iii) $L_{i}^{m}\left(c_{i}^{m}+1, c_{-i}^{m}\right) \leq 0$ if $c_{i}^{m}<n_{i}$,

for every $i=1, \ldots, G$.

Let $\mathcal{C}^{*}(F)$ [resp. $\left.\mathcal{C}^{m}(F)\right]$ be the set of equilibrium structures in the absence [resp. in the presence] of moral hazard when the vector of fixed costs is $F=\left(F_{1}, \ldots, F_{n}\right)$. Characterizing these equilibrium structures occupies the section to follow.

\section{Equilibrium Lobby Structures}

In this section, we are interested in three questions. First, what conditions guarantee the existence of equilibrium lobby structures? Second, assuming that such stable structures exist, what can we say about the equilibrium size of lobbies in the different contexts envisioned by the model? And finally, under what conditions can we infer from equilibrium lobby structures that, contrary to the Olsonian conjecture, moral hazard in teams favors large groups' collective action? We begin the analysis with an introductory example, postponing the statement of general results until the next subsections.

\subsection{A Simple Example}

To facilitate a clear understanding of the impact of moral hazard in teams on lobby formation, it may be helpful to begin with a simple graphical representation. We assume that $G=1$ in order to be able to represent the equilibrium structure in a single graph. Let $w_{1}=1, A_{0}=0.5$, and let $v(a)=a^{2} / 2$. As we want to depict a situation in which the fixed cost is arbitrarily low, we further assume that $F_{1}=0$. 
Figure 1 represents group 1's stability function under both specifications of the model. The grey curve represents $L_{1}\left(c_{1}\right)$, and the black curve represents $L_{1}^{m}\left(c_{1}\right)$.

\section{FIGURE 1 HERE: Stability Functions}

To begin with, consider the without-moral-hazard curve. Applying Definition 1 and assuming $n_{1} \geq 2$, the unique equilibrium membership is easily seen to be $c_{1}^{*}=2$. Indeed, at every $c_{1}<2$, condition (ii) is violated and it is consequently profitable for free-riders to become lobbyists. On the contrary, leaving the lobby is a profitable move for lobbyists whenever $c_{1} \geq 3$. Thus $c_{1}^{*}=2$ is the unique integer satisfying both stability conditions. An immediate consequence of this is that, even if the exogenous cost of forming the lobby is zero, group 1 comprises $n_{1}-2$ free-riders in the equilibrium of the game without moral hazard.

Now, let us introduce moral hazard in teams in the game. Looking at the black curve in Figure 1, we can see that $L_{1}^{m}\left(c_{1}\right)>0$ for every $c_{1} \leq 4$, and $L_{1}^{m}\left(c_{1}\right)<0$ for every $c_{1} \geq 5$. This in turn implies that $c_{1}^{m}=4$ must be the unique equilibrium structure of the game with moral hazard. Thus, two individuals who were free-riders in the previous case are now lobbyists, and the size of the lobby is consequently larger in the presence than in the absence of moral hazard: $c_{1}^{m} \geq c_{1}^{*}$.

For any membership $c_{1}$ to survive as an equilibrium structure, it must be that neither lobbyists nor free-riders have an incentive to deviate: while deviation to lobbying may be desirable for a free-rider as a means of raising the win probability, $\pi_{1}$, deviation to free-riding may also be desirable for a lobbyist in order to avoid the cost of contribution, $v\left(a_{1}\right)$. An intuition for the above result can be obtained by comparing the two cost-of-contribution curves in Figure 2. Indeed, the cost of contribution appears to be quite different depending on whether the lobby faces moral hazard or not. Inspecting first the problem solved by cooperating lobbyists in the absence of moral hazard, we see that we can break the effect of the size change $\left(d c_{i}>0\right)$ on individual contributions into two effects: (i) a positive effect from the increase in the marginal gain from individual contributions (a marginal increase of $a_{1}$ induces a larger increase of group 1's win probability), and (ii) a negative effect from the fact that the same level of aggregate effort, $A_{1}=c_{1} a_{1}$, requires lower individual contributions. Thus, even if the second effect dominates, it is attenuated by the first one. As a result, even when $c_{1}$ is large, lobbyists have strong incentive to leave the lobby in order to escape the onerous cost of contribution to lobbying.

The positive effect of the size on individual contribution dies out when the lobby faces moral hazard, for lobbyists no longer internalize the positive 
impact of their contribution on the other members of the lobby. With moral hazard in teams, an increase in $c_{1}$ only strengthens lobbyists' incentives to free ride their partners, thereby lessening individual contributions to lobbying: in Figure 2, the black curve lies everywhere below the grey one. This makes lobbying sufficiently attractive to induce some free-riders to join the lobby.

\section{FIGURE 2 HERE: Costs of Contributions}

This example illustrates the simple fact that, although moral hazard in teams causes individual contributions to decline, it may also raise the lobby size by reducing individual contribution costs.

\subsection{Existence and Characterization of Equilibrium Mem- berships}

Equipped with a general intuition, we now turn to the formal analysis. Before worrying about the features of equilibrium structures, it is important to ask whether such structures are likely to exist. The following proposition provides a general existence result, which motivates the analysis to follow.

Proposition 1 An equilibrium structure exists both in the absence and in the presence of moral hazard in teams. That is, for any $F \in \mathbb{R}_{++}^{G}$,

$$
\mathcal{C}^{*}(F) \neq \emptyset \text { and } \mathcal{C}^{m}(F) \neq \emptyset \text {. }
$$

Thus, no specific condition is needed to guarantee the existence of equilibrium structures.

We propose now to investigate whether the intuition provided in the above example carries over to the general model with several groups. This appears far less obvious, however, and it turns out that an additional assumption is needed here. Let $A^{m}\left(c_{i}, c_{-i}\right) \equiv A_{0}+\sum_{j=1}^{G} c_{j} a_{j}^{m}\left(c_{j}, c_{-j}\right)$ be the equilibrium level of total contributions in the presence of moral hazard, and let $\eta_{i}\left(c_{i}, c_{-i}\right)$ stand for its elasticity with respect to the size of lobby $i$ :

$$
\eta_{i}\left(c_{i}, c_{-i}\right) \equiv \frac{c_{i}}{A^{m}\left(c_{i}, c_{-i}\right)} \frac{\partial A^{m}\left(c_{i}, c_{-i}\right)}{\partial c_{i}} .
$$

We will make the following

Assumption $\mathcal{A}$ : For very group $i$ and any vector $c_{-i} \in \mathbb{R}_{+}^{G-1}$ :

$$
\lim _{c_{i} \rightarrow+\infty}\left[\frac{1}{1-\eta_{i}\left(c_{i}, c_{-i}\right)}\right]<\inf _{a} \alpha(a) .
$$


As shown by Subsection 3.1, this assumption is not necessary for our results to hold. It is generally satisfied in cases where $\alpha$ is large (take the example of Subsection 3.1 with $v(a)=a^{3} / 3$, for instance). Intuitively, for a given gap between $a_{i}$ and $a_{i}^{m}$, the larger $\alpha(\cdot)$ the larger the impact of moral hazard on the cost of contribution (and then the incentive to become a lobbyist), $v\left(a_{i}\right)-v\left(a_{i}^{m}\right)$. Note that, even if Assumption $\mathcal{A}$ is a condition on parameters, it does not impose any restriction on groups' size and on the vector of organizational costs, $F$, which are the relevant data in the next propositions. $^{7}$

Let us now turn to the characterization of equilibrium lobby memberships. We start with the important base case in which organized lobbies do not face moral hazard in teams.

Proposition 2 For every $i=1, \ldots, G$, there exists an upper-bound $\bar{c}_{i} \geq 0$ (that does not depend on $\left.n_{i}\right)$ such that $\left(c_{i}^{*}, c_{-i}^{*}\right) \in \mathcal{C}^{*}(F)$ implies $c_{i}^{*} \leq \bar{c}_{i}$.

Proposition 2 asserts the existence of an upper bound on the equilibrium size $c_{i}^{*}$ of each lobby $i$ in the absence of moral hazard in teams. An immediate consequence of this is that large groups $\left(n_{i}>\bar{c}_{i}\right)$ comprise free-riders in any equilibrium.

We now turn to the case where effort is not observable. While Proposition 2 places no restriction on the profile of fixed costs, the next proposition characterizes the equilibrium structures of the game with moral hazard when fixed costs are low.

Proposition 3 Suppose $\mathcal{A}$ holds. For every lobby $i=1, \ldots, G$, there exists $\tilde{n}_{i}>0$ such that the following statement is true whenever $n_{i}>\tilde{n}_{i}$ : for every $c_{i}<n_{i}$, there is $\tilde{F}_{i}>0$ such that, whenever $F_{i}<\tilde{F}_{i}, c_{i}<c_{i}^{m}$ for some $\left(c_{i}^{m}, c_{-i}^{m}\right) \in \mathcal{C}^{m}(F)$.

Of particular importance here is this: if a group is large $\left(n_{i}>\max \left\{\tilde{n}_{i}, \bar{c}_{i}\right\}\right)$, and if its fixed costs are low $\left(F_{i}<\tilde{F}_{i}\right)$, then moral hazard in teams raises the equilibrium size of the lobby that represents this group $\left(c_{i}^{m}>c_{i}^{*}\right)$. Proposition 3 thus confirms the intuitions of Subsection 3.1. As we have visualized in Figure 1, this is something to be expected in groups with moral hazard in teams. A similar logic is at work here: The main reason members of groups with a low fixed cost become lobbyists is that the non-observability of contributions allows them to contribute less than in a world with observable effort, thus raising their incentive to join the lobby.

\footnotetext{
${ }^{7} \mathrm{~A}$ brief inspection of equation (2) indeed reveals that the functions $\left\{a_{i}^{m}\left(c_{i}, c_{-i}\right)\right\}_{i=1}^{G}$, and then $A^{m}\left(c_{i}, c_{-i}\right)$, do not depend on the $n_{i}$ 's and $F$. Consequently, $\mathcal{A}$ only places restrictions on $G, v(\cdot), A_{0}$, and the $w_{i}$ 's.
} 
Moreover, applying Proposition 3 with $c_{i}=n_{i}-1$, we immediately see that, in contrast to the case without moral hazard, group $i$ does not comprise free-riders in equilibrium whenever its organizational cost is sufficiently low.

\subsection{Moral Hazard in Teams and Collective Action}

In the preceding discussion, we considered the impact of moral hazard in teams on lobbies' size. An interesting question now is whether the small individual contribution caused by moral hazard might be swamped by a larger group of contributors, so that the group's equilibrium contribution would be larger than that when cooperation among lobbyists is feasible. As noted by Costain (1980), lobbies representing a large number of individuals may sometimes be very effective in collective action, even if their activities are subject to moral hazard. Focusing on women's lobbies, she argues that, despite the pessimistic predictions of the classical theory of collective action, the strong lobbying effort in support of women's rights in the 1970s should lead to a reassessment of their potential for political influence.

We then turn to groups' aggregate contribution, and ask whether moral hazard may "favor" collective action, in the following sense:

Definition 3 Moral hazard in teams is said to favor group $i$ 's collective action if there exists $\left(c_{i}^{m}, c_{-i}^{m}\right) \in \mathcal{C}^{m}(F)$ such that, for every $\left(c_{i}^{*}, c_{-i}^{*}\right) \in \mathcal{C}^{*}(F)$, $c_{i}^{m} a_{i}^{m}\left(c_{i}^{m}, c_{-i}^{m}\right)>c_{i}^{*} a_{i}\left(c_{i}^{*}, c_{-i}^{*}\right)$.

In other words, moral hazard in teams favors a group's collective action if, and only if, there exists an equilibrium with moral hazard in which the aggregate contribution of that group is larger than its aggregate contribution in any equilibrium without moral hazard. The next proposition gives sufficient conditions for this to happen.

Proposition 4 Suppose $\mathcal{A}$ holds. There exist $\bar{n}_{i}>0$ and $\bar{F}_{i}>0$ such that moral hazard in teams favors group $i$ 's collective action whenever $n_{i}>\bar{n}_{i}$ and $F_{i}<\bar{F}_{i}$.

Unlike the standard theory of collective action, it turns out that moral hazard and groups' size here may favor collective action. While moral hazard decreases individual contributions to lobbying, it also raises the number of these contributions. Proposition 4 states that the second effect dominates the first when the group under consideration is large and its organizational cost is low. It thus makes moral hazard in teams somewhat less detrimental than one might have inferred from the pessimistic Olsonian conclusions. 


\section{Concluding Remarks}

The model used here describes the lobbying process at a fairly high level of abstraction, focusing exclusively on free-riding issues. Our aim, however, is not to provide a comprehensive theory of lobby formation, but to develop a simple intuition for how two different free-riding phenomena interact in this process. By restricting attention only to incentives to free ride, our model has deliberately ignored considerations that may be generated by other factors such as the existence of a collective identity, or some divergence in lobby members' objectives and valuations of the public project (heterogeneity). Such an oversimplification of the collective-action problem has largely been emphasized by empirical studies, like Gupta, Hofstetter and Buss (1997), and Masters and Delaney (1987), and the experimental literature on collective action, like Schneider and Pommerehne (1981), or Ostrom (1998). Before further complicating the game-theoretic model, however, it was worth asking what could be said about the actual impact of moral hazard in teams on lobbies' collective action, when the other factors are abstracted away. Possible generalizations and extensions of the present model are left for future research.

\section{Appendix}

We use the following notation throughout this appendix:

$$
\begin{aligned}
A_{i}\left(c_{i}, c_{-i}\right) & \equiv c_{i} a_{i}\left(c_{i}, c_{-i}\right) \\
A_{-i}\left(c_{i}, c_{-i}\right) & \equiv A_{0}+\sum_{j \neq i} c_{j} a_{j}\left(c_{j}, c_{-j}\right) \\
A\left(c_{i}, c_{-i}\right) & \equiv A_{i}\left(c_{i}, c_{-i}\right)+A_{-i}\left(c_{i}, c_{-i}\right) \\
\tilde{\pi}_{i}\left(c_{i}, c_{-i}\right) & \equiv A_{i}\left(c_{i}, c_{-i}\right) / A\left(c_{i}, c_{-i}\right)
\end{aligned}
$$

for every $i=1, \ldots, G$. Similar notation applies to the with-moral-hazard case with a superscript " $m$ " indicating the difference. For instance, $A_{i}^{m}\left(c_{i}, c-i\right) \equiv$ $c_{i} a_{i}^{m}\left(c_{i}, c_{-i}\right)$.

\section{Proof of Proposition 1}

Denote by $C_{i} \equiv\left\{0,1, \ldots, n_{i}\right\}$ the set of all possible sizes of lobby $i$, and by $C \equiv \times_{i=1}^{G} C_{i}$ the set of all possible lobby structures. We construct a self-map $\varphi: C \rightarrow C$, observe that a fixed point of $\varphi$ constitutes an equilibrium lobby structure, and prove that $\varphi$ has a fixed point. 
We construct $\varphi\left(c_{1}, \ldots, c_{G}\right)=\left(\varphi_{1}\left(c_{-1}\right), \ldots, \varphi_{G}\left(c_{-G}\right)\right)$ as follows. First, if $L_{i}\left(n_{i}, c_{-i}\right) \geq 0$, then $\varphi_{i}\left(c_{-i}\right)=n_{i}$. Otherwise, if $L_{i}\left(n_{i}-1, c_{-i}\right) \geq 0$ and $L_{i}\left(n_{i}, c_{-i}\right)<0$, then $\varphi_{i}\left(c_{-i}\right)=n_{i}-1$. Thus, $\varphi_{i}\left(c_{-i}\right)$ is equal to the largest $c_{i} \in C_{i}$ such that $L_{i}\left(c_{i}, c_{-i}\right) \geq 0$ and $L_{i}\left(c, c_{-i}\right)<0$ for every integer $c>c_{i}$, $\varphi_{i}\left(c_{-i}\right)=c_{i}$. If such a $c_{i}$ does not exist, then $\varphi_{i}\left(c_{-i}\right)=0$. It is easy to see that a fixed point of $\varphi$ satisfies all the conditions of Definition 1.

In order to show that $\varphi$ has a fixed point, we now check that all the conditions of the Caristi's Fixed Point Theorem are satisfied. Consider the complete metric space $(C, d)$, where $d\left(c, c^{\prime}\right) \equiv \sum_{i=1}^{G}\left|c_{i}-c_{i}^{\prime}\right|$ for all $c$ and $c^{\prime}$ in $C$, and define the continuous (and then lower semicontinuous) function $f: C \rightarrow \mathbb{R}$ as

$$
f(c) \equiv \frac{1}{1-n} d(c, \varphi(c)),
$$

for every $c \in C$. Note that $f$ is bounded from below by $n / n-1$, and

$$
\begin{aligned}
f(c)-f(\varphi(c)) & =\frac{1}{1-n}\left[d(c, \varphi(c))-d\left(\varphi(c), \varphi^{(2)}(c)\right)\right] \\
& \geq \frac{1}{1-n}[d(c, \varphi(c))-n d(c, \varphi(c))] \\
& =d(c, \varphi(c))
\end{aligned}
$$

for every $c \in C$ such that $\varphi(c) \neq c$ (it is easy to see that, otherwise, $f(c)-f(\varphi(c))=d(c, \varphi(c)))$. The above inequality is due to the fact that $d(c, \varphi(c)) / d\left(\varphi(c), \varphi^{(2)}(c)\right) \geq 1 / n$ when $\varphi(c) \neq c$. Thus, $\varphi$ satisfies all the condtions of Caristi's Fixed Point Theorem and, consequently, has a fixed point. This completes the proof of Proposition 1.

\section{Proof of Proposition 2}

We proceed with a series of lemmas.

Lemma 1 For every $i=1, \ldots, G$,

$$
\frac{\partial \tilde{\pi}_{i}\left(c_{i}, c_{-i}\right)}{\partial c_{i}}>0, \frac{\partial A\left(c_{i}, c_{-i}\right)}{\partial c_{i}}>0 \text {, and } \lim _{c_{i} \rightarrow \infty} \frac{\partial A\left(c_{i}, c_{-i}\right)}{\partial c_{i}}=0 .
$$

Proof: A slight change in the proof of Proposition 2 in Esteban and Ray (2001) gives:

$$
\frac{\partial \tilde{\pi}_{i}\left(c_{i}, c_{-i}\right)}{\partial c_{i}}>0, \frac{\partial A\left(c_{i}, c_{-i}\right)}{\partial c_{i}}>0, \text { and } \frac{\partial A_{-i}\left(c_{i}, c_{-i}\right)}{\partial c_{i}}<0 .
$$


Differentiating equation (1) with respect to $c_{i}$, and rearranging terms, we obtain (with some abuse of notation):

$$
\frac{\partial \tilde{\pi}_{i}\left(c_{i}, c_{-i}\right)}{\partial c_{i}}=\frac{\pi_{i}\left(\alpha\left(a_{i}\right)+1\right)}{\alpha\left(a_{i}\right)+\frac{\pi_{i}}{1-\pi_{i}}}\left[\frac{1}{c_{i}}-\frac{1}{A\left(c_{i}, c_{-i}\right)} \frac{\partial A\left(c_{i}, c_{-i}\right)}{\partial c_{i}}\right] .
$$

But we have just established that this derivative is positive, hence

$$
0<\frac{\partial A\left(c_{i}, c_{-i}\right)}{\partial c_{i}}<\frac{A\left(c_{i}, c_{-i}\right)}{c_{i}}=a_{i}\left(c_{i}, c_{-i}\right)+\frac{A_{-i}\left(c_{i}, c_{-i}\right)}{c_{i}} .
$$

As the marginal benefit from an increase in $c_{i}$ is zero when lobby $i$ 's size is infinite (see equation (1)), $\lim _{c_{i} \rightarrow \infty} a_{i}\left(c_{i}, c_{-i}\right)=0\left(v^{\prime}(0)=0\right)$. Moreover, $A_{-i}\left(c_{i}, c_{-i}\right)$ is decreasing in $c_{i}$. It consequently results from (5) that $\frac{\partial A\left(c_{i}, c_{-i}\right)}{\partial c_{i}} \rightarrow 0$ as $c_{i} \rightarrow \infty$.

Lemma 2 For every $i=1, \ldots, G$, let $\tau_{i}: C \rightarrow(1, \infty)$ be defined as

$$
\tau_{i}\left(c_{i}, c_{-i}\right) \equiv 1+\frac{\tilde{\pi}_{i}\left(c_{i}, c_{-i}\right)-\tilde{\pi}_{i}\left(c_{i}-1, c_{-i}\right)}{\tilde{\pi}_{i}\left(c_{i}-1, c_{-i}\right)\left[1-\tilde{\pi}_{i}\left(c_{i}, c_{-i}\right)\right]} .
$$

Then, for every $c_{-i}, \lim _{c_{i} \rightarrow \infty} \tau_{i}\left(c_{i}, c_{-i}\right)=1$.

Proof: Let $\sigma_{i}$ be defined as

$$
\sigma_{i}\left(c_{i}, c_{-i}\right) \equiv \frac{\tilde{\pi}_{i}\left(c_{i}, c_{-i}\right)-\tilde{\pi}_{i}\left(c_{i}-1, c_{-i}\right)}{\tilde{\pi}_{i}\left(c_{i}-1, c_{-i}\right)\left[1-\tilde{\pi}_{i}\left(c_{i}, c_{-i}\right)\right]} .
$$

To prove the lemma, we must show that $\sigma_{i} \rightarrow 0$ as $c_{i} \rightarrow \infty$. Noting that

$$
\begin{aligned}
\sigma_{i}\left(c_{i}, c_{-i}\right) & =\frac{\tilde{\pi}_{i}\left(c_{i}, c_{-i}\right)-\tilde{\pi}_{i}\left(c_{i}-1, c_{-i}\right)}{\tilde{\pi}_{i}\left(c_{i}-1, c_{-i}\right)} \frac{A\left(c_{i}, c_{-i}\right)}{A_{-i}\left(c_{i}, c_{-i}\right)} \\
& =\frac{A_{i}\left(c_{i}, c_{-i}\right)-A_{i}\left(c_{i}-1, c_{-i}\right)}{\tilde{\pi}_{i}\left(c_{i}-1, c_{-i}\right) A_{-i}\left(c_{i}, c_{-i}\right)}
\end{aligned}
$$

we immediately see that this boils down to showing that $A_{i}\left(c_{i}, c_{-i}\right)-A_{i}\left(c_{i}-1, c_{-i}\right)$ tends to 0 as $c_{i}$ becomes arbitrarily large $\left(A_{-i}\right.$ is bounded from below by $\left.A_{0}\right)$. Applying the Mean Value Theorem to $A_{i}\left(\cdot, c_{-i}\right)$, we know that there exists $\omega \in\left(c_{i}-1, c_{i}\right)$ such that

$$
A_{i}\left(c_{i}, c_{-i}\right)-A_{i}\left(c_{i}-1, c_{-i}\right)=\left.\frac{\partial A_{i}\left(c, c_{-i}\right)}{\partial c}\right|_{c=\omega} .
$$

It then remains to show that this derivatives converges to zero. But Lemma 1 tells us that

$$
\frac{\partial A_{i}\left(c_{i}, c_{-i}\right)}{\partial c}=\frac{\partial A\left(c, c_{-i}\right)}{\partial c}-\frac{\partial A_{-i}\left(c, c_{-i}\right)}{\partial c}=0 .
$$


Lemma 3 There exists $\bar{\delta}>0$ such that the following statement is true whenever $\delta<\bar{\delta}$ :

$$
v(a)>\delta\left[a v^{\prime}(a)\right], \forall a>0
$$

Proof: As $v(a)$ and $a v^{\prime}(a)$ are both strictly increasing functions that are zero at $a=0$, a sufficient condition for (6) to hold is that $v^{\prime}(a)>\delta\left(a v^{\prime}(a)\right)^{\prime}$ for any $a>0$.

Let $\bar{\delta} \equiv 1 /\left(1+\sup _{a>0} \alpha(a)\right)(\bar{\delta}$ is well-defined since $\alpha$ is assumed to be bounded from above). Therefore, for all $\delta<\bar{\delta}$, we have

$$
\frac{1}{\delta}>1+\frac{a v^{\prime \prime}(a)}{v^{\prime}(a)},
$$

or

$$
\delta\left[v^{\prime}(a)+a v^{\prime \prime}(a)\right]<v^{\prime}(a), \forall a \in B .
$$

This completes the proof of Lemma 3.

We now complete the proof of the main proposition. Define $\delta_{i}\left(c_{i}, c_{-i}\right)$ as

$$
\delta_{i}\left(c_{i}, c_{-i}\right) \equiv\left(\tau_{i}\left(c_{i}, c_{-i}\right)-1\right) \frac{1}{\tilde{\pi}_{i}\left(c_{i}, c_{-i}\right)+\tau_{i}\left(c_{i}, c_{-i}\right)\left(1-\tilde{\pi}_{i}\left(c_{i}, c_{-i}\right)\right)},
$$

and note that, by Lemma 2, it tends to zero as $c_{i}$ gets arbitrarily large (it is easy to check that $\tilde{\pi} \rightarrow 1$ as $\left.c_{i} \rightarrow \infty\right)$. This implies that, for every $c_{-i} \in C_{-i} \equiv \times_{j \neq i} C_{j}$, there exists $\bar{c}_{i}\left(c_{-i}\right)>0$ such that $\delta_{i}<\bar{\delta}$ whenever $c_{i}>\bar{c}_{i}\left(c_{-i}\right)$.

Now, let $\left(c_{i}, c_{-i}\right) \in \mathcal{C}^{*}(F)$ and suppose that, contrary to the statement of the proposition, $c_{i}>\bar{c}_{i} \equiv \max _{c_{-i} \in C_{-i}}$. It follows from Lemma 3 that

$$
\begin{aligned}
L_{i}\left(c_{i}, c_{-i}\right) & =\left[\frac{c_{i}}{c_{i}\left(1+\gamma_{i}\left(c_{i}, c_{-i}\right)\right)}-\frac{c_{i}-1}{\left(c_{i}-1\right)\left(1+\left(1+\gamma_{i}\left(c_{i}-1, c_{-i}\right)\right)\right.}\right] w_{i} \\
& -v\left(a_{i}\left(c_{i}, c_{-i}\right)\right) \\
& =a_{i}\left(c_{i}, c_{-i}\right) v^{\prime}\left(a_{i}\left(c_{i}, c_{-i}\right)\right) \delta_{i}\left(c_{i}, c_{-i}\right)-v\left(a_{i}\left(c_{i}, c_{-i}\right)\right)<0
\end{aligned}
$$

where the second equality is due to equation (1). But this is a contradiction with $\left(c_{i}, c_{-i}\right)$ being an equilibrium structure. 


\section{Proof of Proposition 3}

Suppose first that, for every $c_{-i}$,

$$
\ell_{i}^{m}\left(c_{i}, c_{-i}\right) \equiv Q_{i}^{m}\left(c_{i}, c_{-i}\right)-Q_{i}^{m}\left(c_{i}-1, c_{-i}\right)>v\left(a_{i}^{m}\left(c_{i}, c_{-i}\right)\right)
$$

at some $c_{i}<n_{i}$. This implies that there exists $\tilde{F}_{i}\left(c_{i}\right)>0$ such that, for every $c_{-i}, L_{i}^{m}\left(c_{i}, c_{-i}\right) \equiv \ell_{i}^{m}\left(c_{i}, c_{-i}\right)-v\left(a_{i}^{m}\left(c_{i}, c_{-i}\right)\right)-F_{i} / c_{i}>0$ whenever $F_{i}<\tilde{F}_{i}\left(c_{i}\right)$. This in turn implies that there exists an equilibrium structure, $\left(c_{i}^{m}, c_{-i}^{m}\right)$, such that $c_{i}^{m}>c_{i}$ (Definition 2 and Proposition 1 ).

Let us show (7). To do so, note first that, using equation (2) and rearranging terms, we can express $\ell_{i}^{m}\left(c_{i}, c_{-i}\right)$ as follows:

$$
\ell_{i}^{m}\left(c_{i}, c_{-i}\right)=a_{i}^{m}\left(c_{i}, c_{-i}\right) v^{\prime}\left(a_{i}^{m}\left(c_{i}, c_{-i}\right)\right) \delta_{i}^{m}\left(c_{i}, c_{-i}\right),
$$

where

$$
\delta_{i}^{m}\left(c_{i}, c_{-i}\right) \equiv c_{i} \frac{\tilde{\pi}_{i}^{m}\left(c_{i}, c_{-i}\right)-\tilde{\pi}_{i}^{m}\left(c_{i}-1, c_{-i}\right)}{\tilde{\pi}_{i}^{m}\left(c_{i}, c_{-i}\right)\left[1-\tilde{\pi}_{i}^{m}\left(c_{i}, c_{-i}\right)\right]} .
$$

Hence, equation (7) holds for a given $c_{-i}$ if $\delta_{i}^{m}\left(c_{i}, c_{-i}\right)>1 / \alpha\left(a_{i}^{m}\left(c_{i}, c_{-i}\right)\right)$, or

$$
c_{i}\left[\tilde{\pi}_{i}^{m}\left(c_{i}, c_{-i}\right)-\tilde{\pi}_{i}^{m}\left(c_{i}-1, c_{-i}\right)\right]>\frac{\tilde{\pi}_{i}^{m}\left(c_{i}, c_{-i}\right)\left[1-\tilde{\pi}_{i}^{m}\left(c_{i}, c_{-i}\right)\right]}{\alpha\left(a_{i}^{m}\left(c_{i}, c_{-i}\right)\right)} .
$$

From the Mean Value Theorem, there exists $\theta \in\left(c_{i}-1, c_{i}\right)$ such that

$$
\tilde{\pi}_{i}^{m}\left(c_{i}, c_{-i}\right)-\tilde{\pi}_{i}^{m}\left(c_{i}-1, c_{-i}\right)=\left.\frac{\partial \tilde{\pi}_{i}^{m}\left(c, c_{-i}\right)}{\partial c}\right|_{c=\theta} .
$$

As $\theta<c_{i}$ and $\tilde{\pi}_{i}^{m}\left(c_{i}, c_{-i}\right)$ is strictly increasing in $c_{i}$ (Proposition 2 in Esteban and Ray, 2001), inequality (8) holds whenever

$$
\left.c_{i} \frac{\partial \tilde{\pi}_{i}^{m}\left(c, c_{-i}\right)}{\partial c}\right|_{c=\theta}>\frac{\tilde{\pi}_{i}^{m}\left(c_{i}, c_{-i}\right)\left[1-\tilde{\pi}_{i}^{m}\left(\theta, c_{-i}\right)\right]}{\alpha\left(a_{i}^{m}\left(c_{i}, c_{-i}\right)\right)} .
$$

Then, differentiating (2) and rearranging terms yields:

$\frac{\partial \tilde{\pi}_{i}^{m}\left(c, c_{-i}\right)}{\partial c}=\frac{\tilde{\pi}_{i}^{m}\left(c, c_{-i}\right)}{c} \frac{\alpha\left(a_{i}^{m}\right)}{\alpha\left(a_{i}^{m}\right)+\frac{\tilde{\pi}_{i}^{m}\left(c, c_{-i}\right)}{1-\tilde{\pi}_{i}^{m}\left(c, c_{-i}\right)}}-\frac{\tilde{\pi}_{i}^{m}\left(c, c_{-i}\right)\left(1+\alpha\left(a_{i}^{m}\right)\right)}{\alpha\left(a_{i}^{m}\right)+\frac{\tilde{\pi}_{i}^{m}\left(c, c_{-i}\right)}{1-\tilde{\pi}_{i}^{m}\left(c, c_{-i}\right)}} t\left(c, c_{-i}\right)$

where

$$
t\left(c_{i}, c_{-i}\right) \equiv \frac{1}{A^{m}\left(c_{i}, c_{-i}\right)} \frac{\partial A^{m}\left(c_{i}, c_{-i}\right)}{\partial c_{i}} .
$$


Therefore, (9) can be rewritten as

$$
\begin{gathered}
\frac{c_{i}}{\theta} \frac{\tilde{\pi}_{i}^{m}\left(\theta, c_{-i}\right) \alpha\left(a_{i}^{m}\left(\theta, c_{-i}\right)\right)}{\left[1-\tilde{\pi}_{i}^{m}\left(\theta, c_{-i}\right)\right] \alpha\left(a_{i}^{m}\left(\theta, c_{-i}\right)\right)+\tilde{\pi}_{i}^{m}\left(\theta, c_{-i}\right)}-\frac{\tilde{\pi}_{i}^{m}\left(c_{i}, c_{-i}\right)}{\alpha\left(a\left(c_{i}, c_{-i}\right)\right)}> \\
\frac{\tilde{\pi}_{i}^{m}\left(\theta, c_{-i}\right)\left[1+\alpha\left(a_{i}^{m}\left(\theta, c_{-i}\right)\right)\right]}{\left[1-\tilde{\pi}_{i}^{m}\left(\theta, c_{-i}\right)\right] \alpha\left(a_{i}^{m}\left(\theta, c_{-i}\right)\right)+\tilde{\pi}_{i}^{m}\left(\theta, c_{-i}\right)} c_{i} t\left(\theta, c_{-i}\right) .
\end{gathered}
$$

As $\theta \rightarrow \infty$ when $c_{i} \rightarrow \infty\left(\theta>c_{i}-1\right)$, we can see that, under Assumption $\mathcal{A}$, the above condition is satisfied when $c_{i}$ is arbitrarily large. Consequently, there exists $\tilde{c}_{i}\left(c_{-i}\right)>0$ such that inequality (8) holds whenever $c_{i}>\tilde{c}_{i}\left(c_{-i}\right)$.

Now, let $\tilde{c}_{i} \equiv \max _{c_{-i} \in C_{-i}} \tilde{c}_{i}\left(c_{-i}\right)$. Then, inequality (7) holds for every $c_{-i} \in C_{-i}$ whenever $c_{i}>\tilde{c}_{i}$, and we obtain Proposition 3 by setting $\tilde{n}_{i}=\tilde{c}_{i}$. Indeed, if $c_{i} \leq \tilde{c}_{i}$, the stability function is always strictly positive at $\tilde{c}_{i}+1$ for any $F_{i}<\tilde{F}_{i}\left(\tilde{c}_{i}+1\right)$ and there is consequently an equilibrium structure $\left(c_{i}^{m}, c_{-i}^{m}\right)$ such that $c_{i}^{m}>\tilde{c}_{i}+1>c_{i}$. The same reasoning applies if $c_{i}>\tilde{c}_{i}$ by taking $F_{i}<\tilde{F}_{i}\left(c_{i}\right)$. This completes the proof of the proposition.

\section{Proof of Proposition 4}

The proof of Proposition 4 hinges on the following result.

Lemma 4 Given $c_{-i} \in \mathbb{R}_{+}^{G-1}$,

$$
\frac{\partial A_{i}^{m}\left(c_{i}, c_{-i}\right)}{\partial c_{i}}>0 \text { and } \lim _{c_{i} \rightarrow \infty} A_{i}^{m}\left(c_{i}, c_{-i}\right)=\infty .
$$

Proof: By definition,

$$
A_{i}^{m}\left(c_{i}, c_{-i}\right) \equiv \tilde{\pi}_{i}^{m}\left(c_{i}, c_{-i}\right) A^{m}\left(c_{i}, c_{-i}\right) .
$$

Since both terms on the right-hand side are increasing in $c_{i}$, so is $A_{i}^{m}$. This implies that if $A_{i}^{m}$ is bounded above, there exists $K_{i}>0$ such that $\lim _{c_{i} \rightarrow \infty} A_{i}^{m}\left(c_{i}, c_{-i}\right)=K_{i}$. But since $\tilde{\pi}_{i}^{m}\left(c_{i}, \hat{c}_{-i}\right) \leq 1$, this in turn implies from (10) that there exists $K>0$ such that $\lim _{c_{i} \rightarrow \infty} A^{m}\left(c_{i}, c_{-i}\right)=K$. Thus we get a contradiction since equation (2)

$$
\frac{A_{-i}^{m}\left(c_{i}, c_{-i}\right) w_{i}}{A^{m}\left(c_{i}, c_{-i}\right)^{2}}=v^{\prime}\left(\frac{A_{i}^{m}\left(c_{i}, c_{-i}\right)}{c_{i}}\right)
$$

does not hold for limiting values of $c_{i}$. Indeed, the right-hand side converges to zero, whereas the left-hand side always exceeds $A_{0} w_{i} / K^{2}>0$. As a consequence, for a given $c_{-i}$, we have

$$
\frac{\partial A_{i}^{m}\left(c_{i}, c_{-i}\right)}{\partial c_{i}}>0 \text { and } \lim _{c_{i} \rightarrow \infty} A_{i}^{m}\left(c_{i}, c_{-i}\right)=\infty
$$


Now, for every $i$, let $\hat{c}_{i} \geq 0$ be defined as follows

$$
\hat{c}_{i} \equiv\left\{\begin{array}{cl}
\bar{c}_{i} & \text { if } \bar{c}_{i} \leq n_{i}, \\
n_{i} & \text { otherwise }
\end{array}\right.
$$

where $\bar{c}_{i}$ is the upper-bound defined in Proposition 2. Note that the set $S \equiv \bigcup_{i=1}^{G}\left[0, \hat{c}_{i}\right]$ is nonempty and compact. Then, by continuity of $A_{i}$, the upper-bound $\bar{A}_{i} \equiv \max \left\{A_{i}\left(c_{i}, c_{-i}\right):\left(c_{i}, c_{-i}\right) \in S\right\}>0$ is well-defined.

From Lemma 4 , there exists $n_{i}\left(c_{-i}\right)>0$ such that $A_{i}^{m}\left(n_{i}\left(c_{-i}\right), c_{-i}\right)=\bar{A}_{i}$, and $A_{i}^{m}\left(n_{i}, c_{-i}\right) \geq A_{i}^{m}\left(n_{i}\left(c_{-i}\right), c_{-i}\right)$ whenever $n_{i} \geq n_{i}\left(c_{-i}\right)$. We set $\bar{n}_{i} \equiv$ $\max \left\{n_{i}\left(c_{-i}\right): c_{-i} \in \times_{j \neq i}\left\{0, \ldots, n_{j}\right\}\right\}$.

Now, applying Proposition 3 with $c_{i}=\bar{n}_{i}$, we know that there exists $\bar{F}_{i}>0$ and some $\left(c_{i}^{m}, c_{-i}^{m}\right) \in \mathcal{C}^{m}(F)$ such that $c_{i}^{m}>\bar{n}_{i}$ whenever $F_{i}<\bar{F}_{i}$.

Thus, for any structure $\left(c_{i}^{*}, c_{-i}^{*}\right) \in \mathcal{C}^{*}(F)$, we obtain

$$
A_{i}^{m}\left(c_{i}^{m}, c_{-i}^{m}\right)>A_{i}^{m}\left(\bar{n}_{i}, c_{-i}^{m}\right) \geq \bar{A}_{i} \geq A_{i}\left(c_{i}^{*}, c_{-i}^{*}\right),
$$

whenever $F_{i} \leq \bar{F}_{i}$ and $n_{i}>\bar{n}_{i}$. Proposition 3 establishes the first inequality, and Proposition 2 establishes the last inequality. This ends the proof of the proposition.

\section{References}

[1] Agrawal, A., Goyal, S., 2001. Group Size and Collective Action. ThirdParty Monitoring in Common-Pool Resources. Comparative Political Studies 34, 63-93.

[2] Austen-Smith, D., 1981. Voluntary Pressure Groups. Economica 48, 143153.

[3] Carraro, C., Siniscalco, D., 1997. Strategies for the International Protection of the Environment. Journal of Public Economics 52, 309-328.

[4] Costain, A.N., 1980. The Struggle for a National Women's Lobby: Organizing Diffuse Interest. Western Political Quarterly 33, 476-491.

[5] d'Aspremont, C.A., Jacquemin, A., Gabszewicz, J.J., Weymark, J., 1983. On the Stability of Collusive Price Leadership. Canadian Journal of Economics 16, 17-25. 
[6] Espinosa, M.P., Macho-Stadler, I., 1996. Endogenous Formation of Competing Partnerships with Moral Hazard. Games and Economic Behavior 44, 172-183.

[7] Esteban, J., Ray, D., 2001. Collective Action and the Group Size Paradox. American Political Science Review 95, 663-672.

[8] Felli, L., Merlo, A., 2006. Endogenous Lobbying. Journal of the European Economic Association 4, 180-215.

[9] Grossman, G.M., Helpman, E., 2001. Special Interest Politics. Cambridge, Mass.: MIT Press.

[10] Gupta, D.K., Hofstetter, C.R., Buss, T.F., 1997. Group Utility in the Micro Motivation of Colletive Action: The Case of Membership in the AARP. Journal of Economic Behavior and Organization 32, 301-320.

[11] Hojnacki, M., Kimball, D.C., 2001. PAC Contributions and Lobbying Contacts in Congressional Committees. Political Research Quarterly 54, 161-180.

[12] Holmström, B., 1982. Moral Hazard in Teams. Bell Journal of Economics $13,324-340$.

[13] Le Breton, M., Salanie, F., 2003. Lobbying under Political Uncertainty. Journal of Public Economics 87, 2589-2610.

[14] Martimort, D., 2004. Delegated Common Agency under Moral Hazard and the Formation of Interest Groups. University of Toulouse, Mimeo.

[15] Masters, M.F., Delaney, J.T., 1987. Union Political Activities: A Review of the Empirical Literature. Industrial and Labor Relations Review 40, 336-353.

[16] Mitra, D., 1999. Endogenous Lobby Formation and Endogenous Protection: A Long-Run Model of Trade Policy Determination. American Economic Review 89, 1116-1134.

[17] Mueller, D., 2003. Public Choice III. Cambridge, Cambridge University Press.

[18] Murdoch, J.C., Sandler, T., Vijverberg, W.P.M., 2003. The Participation Decision versus the Level of Participation in an Environmental Treaty: a Spatial Probit Analysis. Journal of Public Economics 87, 337362. 
[19] Olson, M., 1965. The Logic of Collective Action. Cambridge, MA: Harvard University Press.

[20] Ostrom, E., 1998. A Behavioral Approach to the Rational Choice Theory of Collective Action. American Political Science Review 92, 1-22.

[21] Pecorino, P., 1998. Is There a Free-Rider Problem in Lobbying? Endogenous Tariffs, Trigger Strategies, and the Number of Firms. American Economic Review 88, 652-660.

[22] Pecorino, P., 2001. Can By-Product Lobbying Firms Compete? Journal of Public Economics 82, 377-397.

[23] Petrakis, E., Xepapadeas, A., 1996. Environmental Consciousness and Moral Hazard in International Aggreements to Protect the Environment. Journal of Public Economics 60, 95-110.

[24] Sandler, T., Hartley, K., 2001. Economics of Alliances: The Lessons for Collective Action. Journal of Economic Literature XXXIX, 869-896.

[25] Schneider, F., Pommerehne, W.W., 1981. Free Riding and Collective Action: An Experiment in Public Microeconomics. Quarterly Journal of Economics 96, 689-704. 


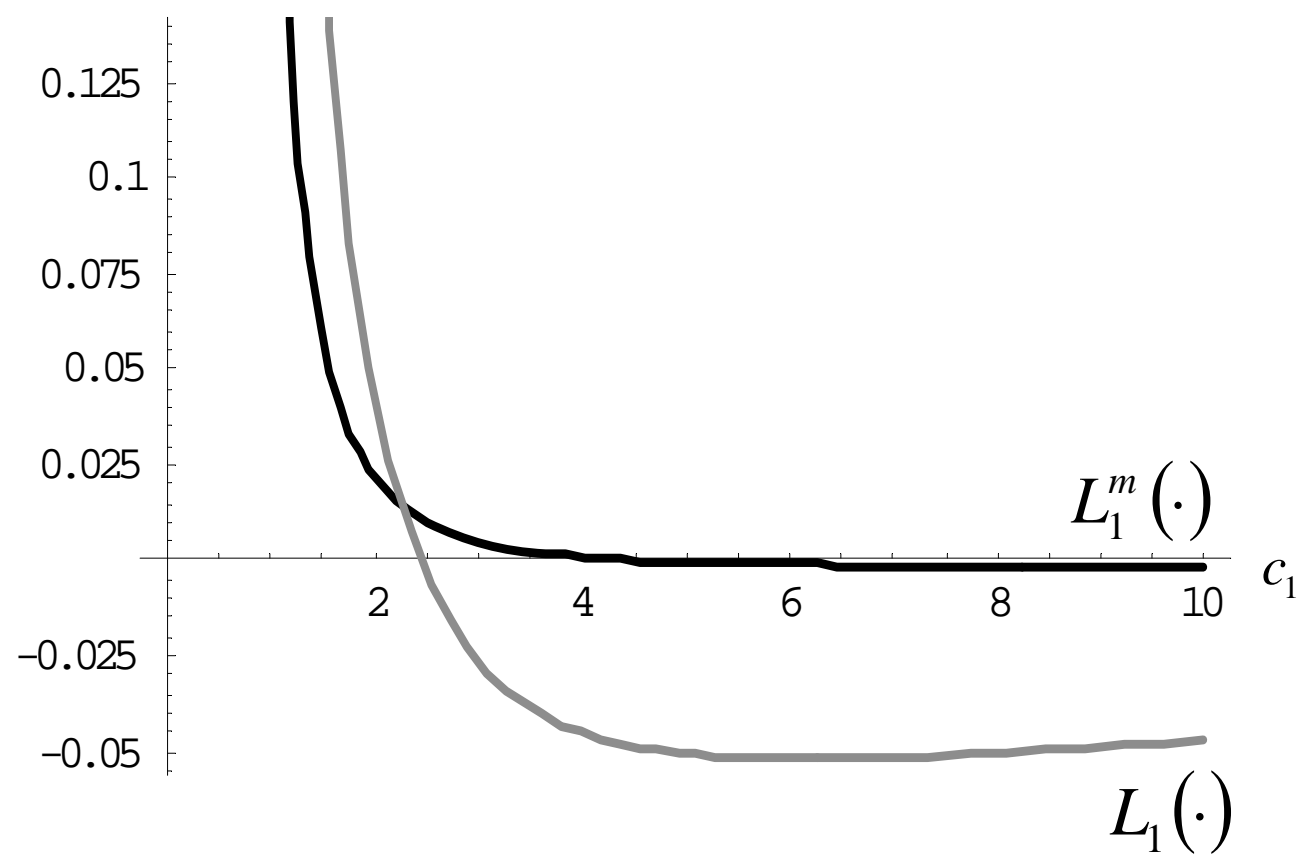

Figure 1; Stability Functions

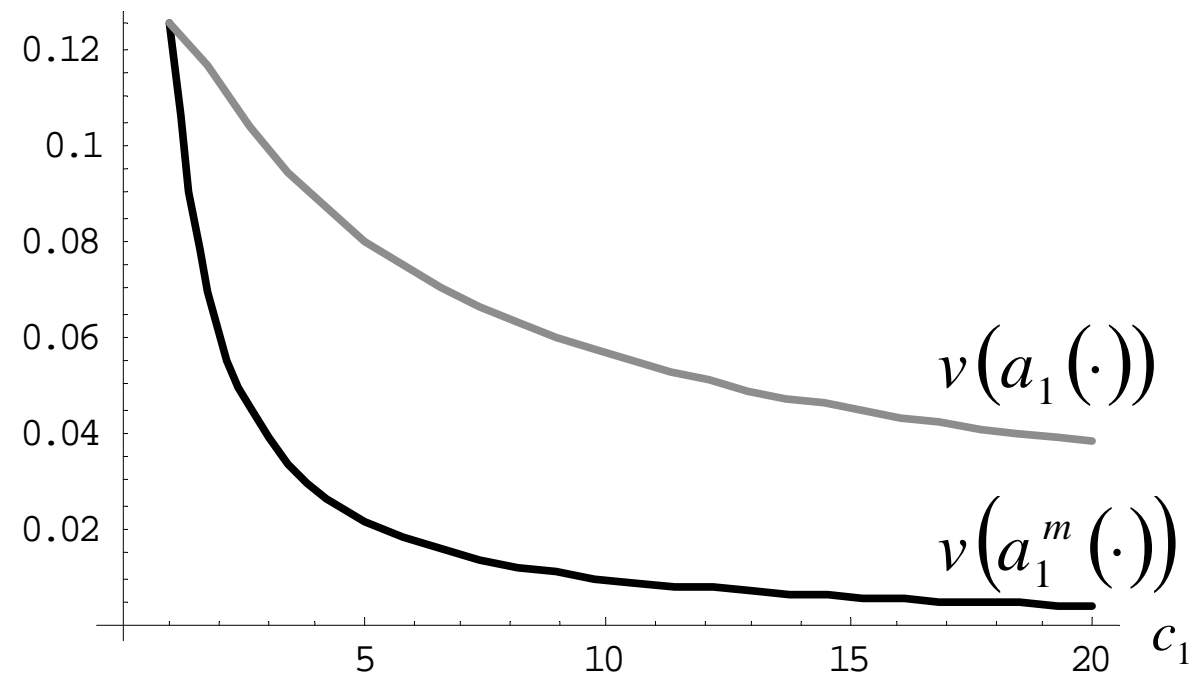

Figure 2: Costs of Contributions 